Miura, M., M. Kubota, S. Kurinobu and A. Watanabe (2006): Clone identification of Hinoki cypress plus-tree using SSR markers in Kanto breeding region. Kanto J For Res 57: 135-136.

MiURA, M. and A. WATANABE (2007): Clone identification of Hinoki cypress plus-tree using 7 SSR markers and detection of contaminated clones in a breeding orchard. Kanto J For Res 58: 245-246.

Moriguchi, Y., N. TANi, S. Itoo, F. Kanehira, K. TANaKA, H. Yomogida, H. TAIRA and Y. Tsumura (2005): Gene flow and mating system in five Cryptomeria japonica D. Don seed orchards as revealed by analysis of microsatellite markers. Tree Genetics and Genomes 1: 174-183.

Nakao, Y., H. Iwata, A. Matsumoto, Y. Tsumura and N. TOMARU (2001): Highly polymorphic microsatellite markers in hinoki (Chamaecyparis obtusa). Can J For Res 31: 2248-2251.

RAYMOND, M. and F. RousseT (1995): GENEPOP (version 1.2): population genetics software for exact tests and ecumenicism. J Hered 86: 248-249.

Rozen, S. and H. J. Skaletsky (2000): Primer3 on the WWW for general users and for biologist programmers, pp. 365-386. In: Bioinformatics Methods and Protocols: Methods in Molecular Biology, edited by S. KRAWETZ and S. Misener. Humana Press, Totowa/NJ.
SCHUELKE, M. (2000): An economic method for the fluorescent labeling of PCR fragments. Nature Biotechnology 18: 233-234.

SHIRAISHI, S., H. KAMINAKA and N. OHYAMA (1987): Genetic variation and differentiation recognized at two allozyme loci in Hinoki (Chamaecyparis obtusa). J Jpn For Soc 69: 88-93 (in Japanese with English summary).

Smouse, P. E., R. Peakall and E. Gonzales (2008): A heterogeneity test for fine-scale genetic structure. Mol Ecol 17: 3389-3400.

TAKAHAShI, T., N. TANI, H. TAIRA and Y. Tsumura (2005): Microsatellite markers reveal high allelic variation in natural populations of Cryptomeria japonica near refugial areas of the last glacial period. J Plant Res 118: 83-90.

Tsumura, Y., A. Matsumoto, N. TANi, T. Ujino-Ihara, T. KADO, H. IwATA and K. UCHIDA (2007): Genetic diversity and the genetic structure of natural populations of Chamaecyparis obtusa: implications for management and conservation. Heredity 99: 161-172.

UChida, K., N. Tomaru, T. TOMarU, C. YAmamoto and K. OHBA (1997): Allozyme variation in natural populations of hinoki, Chamaecyparis obtusa and its comparison with hinoki plus-trees selected from artificial stands. Breed Sci 47: 7-14.

\title{
Short Note: Cross-Species Amplification and Characterization of Pinus Chloroplast Microsatellite Markers in Cedrus deodara Roxb.
}

\author{
By H. S. Ginwal *), P. Chauhan, S. Barthwal, A. Sharma and R. Sharma ${ }^{1)}$ \\ Division of Genetics and Tree Propagation, Forest Research Institute, \\ P.O.I.P.E Kaulagarh Road, Dehradun 248195 (Uttarakhand), India
}

(Received $18^{\text {th }}$ December 2009)

\begin{abstract}
The study reports the transferability of chloroplast microsatellite markers developed for Pinus species to Cedrus deodara. A total of 49 primer pairs (both nuclear and chloroplast) of Pinus species were tested in $C$. deodara out of which 21 chloroplast primers showed positive amplification and 20 were found polymorphic. The primers were screened on 100 adult trees of two natural populations of $C$. deodara. Using twenty cpSSR primers, a total of 64 variants were found which combined in 70 different haplotypes. The total haplotype diversity in two populations was 0.860 and 0.876 with a mean of 0.868 . These sets of markers can further be used for population genetic studies and characterization in
\end{abstract}

1) Himalayan Forest Research Institute, Panthaghati, Shimla (H.P.) India.

*) Author for correspondence: Dr. H. S. GINwAL.

E-mail: ginwalhs@icfre.org; ginwalhs@rediffmail.com
C. deodara for which no cpSSR markers have been reported till date.

Key words: Cross-amplification, cpSSRs, Cedrus deodara, microsatellite, genetic diversity.

Cedrus deodara (deodar), also known as Indian cedar is the most important among the Indian conifers. It is an important timber species of Western Himalayas at elevation ranging from $1200 \mathrm{~m}$ to $3050 \mathrm{~m}$ (TIWARI, 1994). It covers an area of about 0.2 million hectares in India mainly in the states of Jammu \& Kashmir, Himachal Pradesh and Uttarakhand. The species is in great demand for its timber and had been subjected to exploitation for centuries. Natural deodar forests are under great pressure not only due to human impact but also due to the changing weather conditions. In spite of the importance of $C$. deodara forests, limited information is available on their basic biology and genetic variability. 
As a part of our studies on population genetic analysis of deodar forests of western Himalayas, we report here the results aimed at detecting and testing microsatellites in $C$. deodara. Microsatellites, or simple sequence repeats (SSRs), show many advantages since they are co-dominantly inherited and are generally highly polymorphic. Furthermore, their transferability between closely related species makes them useful for the genetic studies of related species (WEISING et al., 2005). Microsatellites could be of great utility not only in determining the levels of genetic diversity but also in unraveling the genetic structure of the populations and in estimating the levels of gene flow (RAO et al., 2006).

Table 1. - Microsatellite (chloroplast) primer pair sequences, annealing temperature (Tm), product size and repeat motifs that showed positive amplification in Cedrus deodara.

\begin{tabular}{|c|c|c|c|c|c|}
\hline S.No. & Locus & Sequence $\left(\mathbf{5}^{\prime}-\mathbf{3}^{\prime}\right)$ & $\begin{array}{l}\text { Annealing } \\
\text { temperature } \\
\text { ("C) }\end{array}$ & $\begin{array}{l}\text { Product size } \\
\text { range (bp) }\end{array}$ & Repeat motif \\
\hline \multirow{2}{*}{1} & \multirow{2}{*}{ Pt15169* } & F: CTTGGATGGAATAGCAGCC & 58.0 & $120-126$ & $\left(\mathrm{C}_{8}(\mathrm{~T})_{8} \mathrm{~A}(\mathrm{~T})_{8}\right.$ \\
\hline & & R: GGAAGGGCATTAAGGTCATTA & & & \\
\hline \multirow{2}{*}{2} & \multirow{2}{*}{ Pt26081* } & F: CCCGTATCCAGATATACTTCCA & 58.0 & $112-118$ & $(\mathrm{~T})_{14}$ \\
\hline & & R: TGGTTTGATTCATTCGTTCAT & & & \\
\hline \multirow{2}{*}{3} & \multirow{2}{*}{ P130204* } & F: TCATAGCGGAAGATCCTCTTT & 58.0 & $131-143$ & $(A)_{12}(G)_{10}$ \\
\hline & & R: CGGATTGATCCTAACCATACC & & & \\
\hline \multirow{2}{*}{4} & \multirow{2}{*}{ Pt36480* } & F: TTTTGGCTTACAAAATAAAAGAGG & 58.0 & $145-152$ & $(\mathrm{~T})_{11}$ \\
\hline & & R: AAATTCCTAAAGAAGGAAGAGCA & & & \\
\hline \multirow{2}{*}{5} & \multirow{2}{*}{ Pt71936" } & F: TTCATTGGAAATACACTAGCCC & 58.0 & $148-149$ & $(\mathrm{~T})_{16}$ \\
\hline & & R: AAAACCGTACATGAGATTCCC & & & \\
\hline \multirow{2}{*}{6} & \multirow{2}{*}{ Pt109567* } & F: TATTATCGAACAACGAGAATAATCC & 58.0 & $115-126$ & (T) $11 \mathrm{G}(\mathrm{T}) 3$ \\
\hline & & R: TCACTGTCACTCTACAAAACCG & & & \\
\hline \multirow{2}{*}{7} & \multirow{2}{*}{ Pt107148* } & F: GTTCATTCGGGATCCTTAAAA & 58.0 & $119-122$ & $(\mathrm{~T}) 10$ \\
\hline & & R: GTACTTTCCTTCAGCCAATCTG & & & \\
\hline \multirow{2}{*}{8} & \multirow{2}{*}{ Pt102584* } & F: TTCATGTAATTCCCAGATCCA & 58.0 & $127-127$ & $(\mathrm{~T}) 11$ \\
\hline & & R:CATTATGTGCGCGATAATTTC & & & \\
\hline \multirow{2}{*}{9} & \multirow{2}{*}{$P^{\prime} 41093^{*}$} & F: TCCCGAAAATACTAAAAAAGCA & 58.0 & $76-82$ & (T) 11 \\
\hline & & R: CTCATTGTTGAACTCATCGAGA & & & \\
\hline \multirow{2}{*}{10} & \multirow{2}{*}{ Pt45002* } & F: AAGTTGGATTTTACCCAGGTG & 58.0 & $160-163$ & (T) 15 \\
\hline & & R: GAACAAGAGGATTTTTTCTCATACA & & & \\
\hline \multirow[t]{2}{*}{11} & \multirow[t]{2}{*}{ Pt51873* } & F: AATCTTTCTACGGAACGGAAA & 58.0 & $86-92$ & (T) 10 \\
\hline & & R: ATCATT"TGTGCTATGCAATGA & & & \\
\hline \multirow[t]{2}{*}{12} & \multirow[t]{2}{*}{ Pt63718* } & F: CACAAAAGGATTTTTTTTCAGTG & 58.0 & $89-98$ & (T) 9 \\
\hline & & R: CGACGTGAGTAAGAATGGTTG & & & \\
\hline \multirow{2}{*}{13} & Pt79951* & F: CTTTTGTTTTTCAACAATTGCA & 58.0 & $141-149$ & (T) 9 \\
\hline & & R: ACATCTATCTCCCATATCGGC & & & \\
\hline 14 & P187268* & F: GCCAGGGAAAATCGTAGG & 58.0 & $165-178$ & (T) $10 \mathrm{C}(\mathrm{T}) 5$ \\
\hline & & R: AGACGATTAGACATCCAACCC & & & \\
\hline 15 & Pt110048* & F: TAAGGGGACTAGAGCAGGCTA & 58.0 & $88-92$ & $(\mathrm{~T}) 9$ \\
\hline & & R: 'I"ICGATAT"I'GAACCTTGGACA & & & \\
\hline 16 & PCP1289^ & F: 'TCCIGGI'TCCAGAAA'TGGAG & 58.5 & $113-117$ & (T) 17 \\
\hline & & R: TAATTTGGTTCCAGAATTGCG & & & \\
\hline 17 & $\operatorname{PCP}_{434}^{\wedge}$ & F: AAACTGACGTAGATGCCATGG & 58.5 & $131-142$ & (A) 10 \\
\hline 17 & 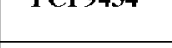 & R: GCGGTATGAGGGAAGAAGC & & & \\
\hline 18 & PCP26106^ & F: AATCCGACAAAAAAGATTCGG & 58.5 & $131-149$ & (A) 14 \\
\hline & & R: GCTCCATTTCACGTGGTTG & & & \\
\hline 10 & РСР36567^ & F: AAAAGAGGAGGAAAAACACCTT & 58.5 & $115-118$ & $(\mathrm{~T}) 11$ \\
\hline 17 & 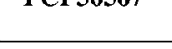 & R: AAGAGCAGACAAGTAAGGGGC & & & \\
\hline 20 & PCP45071^ & F: ACTGGTCTGATCGACCCAAT & 58.5 & $147-152$ & (T) 15 \\
\hline & & R: TTCTACACTTGCGGAAACCC & & & \\
\hline 21 & PCP100842^ & F: TCAATACAAATGATGGGAGTCG & 58.5 & $146-162$ & (A) 12 \\
\hline $2 \mathrm{I}$ & & R: TTTTGCCATATCCTGAAACTCC & & & \\
\hline
\end{tabular}

Adopted from *VENDRAmin et al. (1996), ^PROVAn et al. (1999) 
Table 2. - Haplotype frequency (sorted by overall abundance) in two populations of Cedrus deodara. In the first column the allele size at each of the twenty cpSSR loci studied. In the last column overall frequency of haplotypes is reported.

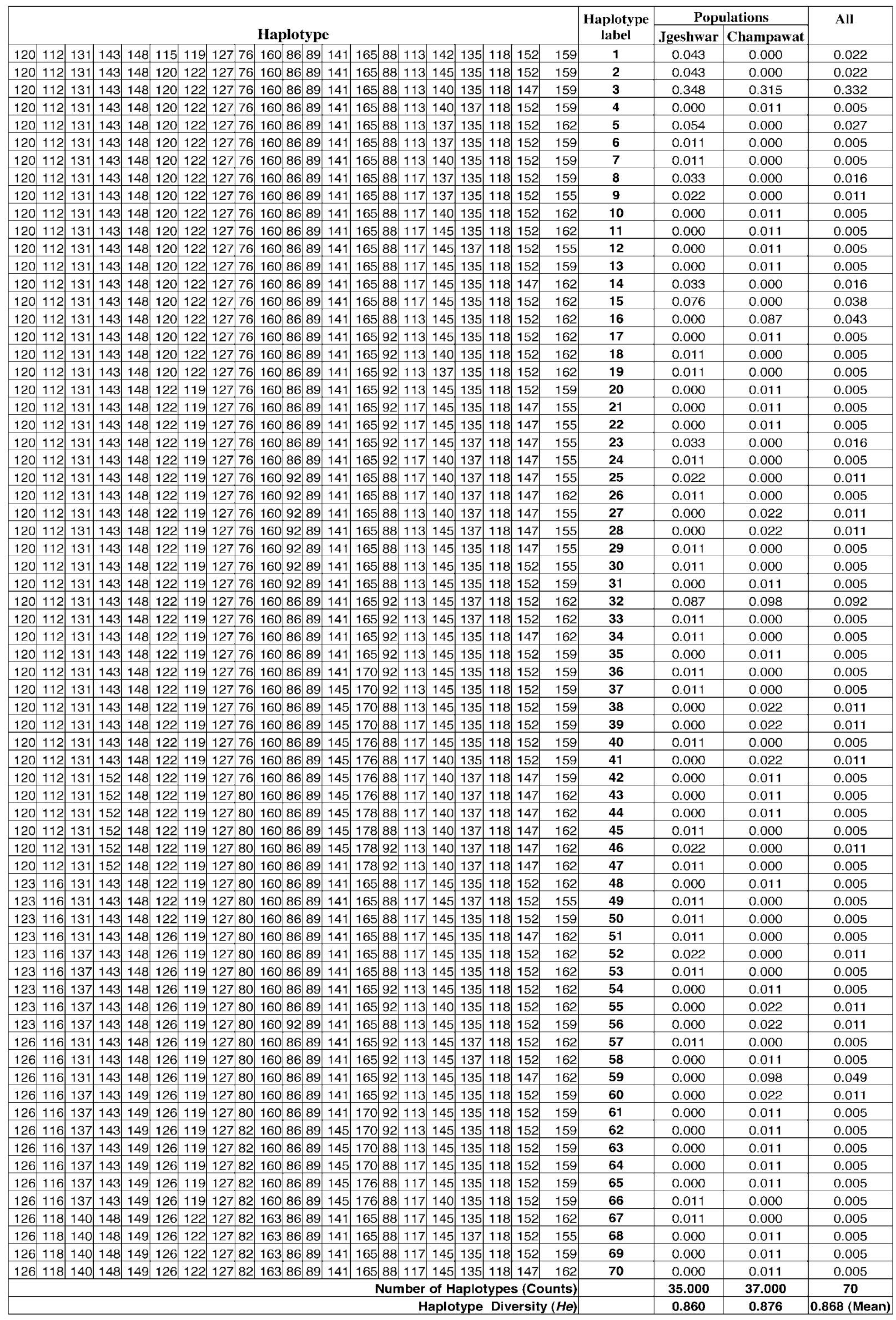


The development of simple sequence repeats (SSRs) from genomic DNA is costly, labor-intensive and timeconsuming process (CHABANE et al., 2005). Moreover, SSR discovery from genomic libraries has proved problematic in conifers, with a low return for effort (RAJORA et al., 2001; HoDGETTs et al., 2001). This is deemed to be because of the large size and repetitive nature of the conifer genome. Hence, microsatellite transfer across the species is a valued methodology. It has been shown that closely related species are more likely to share microsatellite-priming sites than more distantly related ones, but it is possible to transfer microsatellite primers even from distantly related species (LORIEUX et al., 2000).

We examined the transferability of cpSSRs and nuclear SSRs from C. atlantica, Pinus thunbergii, $P$. resinosa, $P$. taeda and $P$. sylvestris to $C$. deodara and their characteristics in C. deodara. Earlier CHAIB et al. (2006), FADY et al. (2003), FADY et al. (2008) and TERRAB et al. (2006) demonstrated that pine cpSSRs Pt15169, Pt63718, Pt71936, Pt87268, Pt26081, Pt36480 and Pt110048 can be amplified in Cedrus. They were not tested in C. deodara, but this was a good indication that their transferability to $C$. deodara can be possible. Here we report the successful transfer of primer pairs designed for the amplification of microsatellite loci in different Pinus species to a member of the same family but separate genus, $C$. deodara. This is the first report wherein cpSSR marker sets have been reported for C. deodara, an important Himalayan conifer.

The individuals tested belonged to two natural populations viz. Champawat forest division (latitide $39^{\circ} 20^{\prime} \mathrm{N}$, longitude $80^{\circ} 07^{\prime} \mathrm{E}$, altitude $1992 \mathrm{~m}$ ) \& Jageshwar forest division (latitide $39^{\circ} 38^{\prime} \mathrm{N}$, longitude $79^{\circ} 51^{\prime} \mathrm{E}$, altitude $1667 \mathrm{~m}$ ) of $C$. deodara from field collection in Uttarakhand. Samples of DNA from the needles were extracted following CTAB protocol (DoYLE and DoYle, 1990). The extracted DNA was quantified and diluted to $30 \mathrm{ng} / \mathrm{\mu l}$ for further use in amplification reactions.

For amplification in $C$. deodara a total of 49 primer pairs (both nuclear and chloroplast) from C. atlantica (CHAIB et al., 2006), P. thunbergii (VENDRAMIN et al., 1996), P. resinosa (Boys et al., 2005), P. taeda (ZHOU et al., 2002) and P. sylvestris (PROVAN et al., 1999) were tested. Loci were initially screened for polymorphism by running PCR products for four individuals on polyacrylamide gel $(8 \%)$ and stained with ethidium bromide $(500 \mu \mathrm{g} /$ Litre). PCR amplification was carried out at $95^{\circ} \mathrm{C}, 5 \mathrm{~min}$ for initial denaturation, followed by 30 cycles of denaturing at $94^{\circ} \mathrm{C}$ for $1 \mathrm{~min}$, primers annealing for $1 \mathrm{~min}$, extension at $72^{\circ} \mathrm{C}$ for $1 \mathrm{~min}$ and then the final extension/termination at $72^{\circ} \mathrm{C}$ for $8 \mathrm{~min}$. The PCR reaction mixture contained $30 \mathrm{ng}$ template DNA, $0.2 \mathrm{mM}$ of each dNTPs (Bangalore Genei, Bangalore, India), $3.0 \mathrm{mM}$ of $\mathrm{MgCl}_{2}, 0.2 \mu \mathrm{M}$ of each of primer pair and 1 unit of Taq DNA Polymerase (Bangalore Genei, Bangalore, India) in a total volume of $15 \mu \mathrm{l}$. Amplification was considered positive when the primers yielded specific PCR products of expected size without multiple bands.
Out of the 49 primers tested, only 21 chloroplast primer pairs yielded amplification products of expected size in $C$. deodara and were selected for fluorescent labelling with 6-FAM and HEX at the forward primers. The labelled primers were further screened for polymorphisms using 100 samples collected from the two natural populations. For genotyping, the PCR products were electrophoresed along with GeneScan ROX 400 internal size standard on an ABI prism 3100 Genetic Analyser (Applied Biosystems). Allele sizes were assigned against the internal size standard and individuals were genotyped using GeneScan analysis software and Genotyper software version 3.7 (Applied Biosystems).

As chloroplast has haploid genomes that are paternally inherited in pines (NEALE and SEDEROFF, 1989; WATANO et al., 1996), hence for the diversity measure, the chloroplast genome was regarded as a single nonrecombining locus and repeat length differences between individuals were scored as haplotypic variants over all cpSSR sites. The effective number of haplotypes for each population was calculated as $n e=1 /\left(\Sigma p i^{2}\right)$, as well as the unbiased haplotype diversity as $H e=[\mathrm{n} /(\mathrm{n}-1)]$ $\left(1-\Sigma p i^{2}\right)$, where $p i$ is the frequency of $\mathrm{i}$-th haplotype and $n$ is the number of individuals analysed (NEI, 1987; AVISE, 1994; VENDRAMIN et al., 1998).

Screening for polymorphism indicated that except for one (Pt102584) the other twenty loci were polymorphic. The characteristics of cpSSRs in C. deodara are summarized in Table 1. The twenty cpSSR loci gave a total of 64 different variants among the 100 individuals of two populations surveyed. The 64 variants were combined into 70 different haplotypes, the frequency distribution of which is reported in Table 2. Only two haplotypes were common to the two populations. The primer Pt102584 though yielded a sharp amplification but was found monomorphic hence can be discarded for further studies. The total haplotype diversity $(\mathrm{He})$ in two populations was 0.860 (Jageshwar) and 0.876 (Champawat) with a mean of 0.868 , which is comparable to the haplotypic diversity reported in Pinus pinaster (VENDRAMIN et $a l ., 1998)$ and in Eastern North American Abies (CLARK et al., 2000). CHAIB et al. (2006) tested the transferability of nSSRs developed in C. atlantica to C. deodara and reported four nSSR out of six to work in a single $C$. deodara sample. However, none of these nSSR worked in our 100 test samples representing two populations of C. deodara. QIAO et al. (2007) indicated that there are reasons to believe that transferability might be more difficult from $C$. atlantica to $C$. deodara than other species of the genus because of their distant phylogenetic relationship. The less transferability of genomic SSRs has also been reported earlier by CHAGNE et al. (2004) in pines. The percentage of chloroplast microsatellites successfully transferred from $P$. thunbergii and $P$. sylvestris was more as compared to the nuclear microsatellites transferred from $P$. taed $a$ and $P$. resinosa in which either no amplification or very poor amplification was observed. The identified chloroplast microsatellite loci are currently being applied to survey the genetic diversity and unraveling the genetic structure of the populations of $C$. deodara forests of western Himalaya. 


\section{Acknowledgements}

The authors are grateful to Director, Forest Research Institute, Dehradun for providing facilities and Indian Council of Forestry Research and Education, Dehradun for financial support for conducting this research.

\section{References}

Avise, J. C. (1994): Molecular markers, natural history and evolution. Chapman and Hall, New York.

Boys, J., M. CHERrY and S. DAYANANDAN (2005): Microsatellite analysis reveals genetically distinct population of Red Pine (Pinus resinosa, Pinaceae). American Journal of Botany 92(5): 833-841.

Chabane, K., G. A. Ablett and G. M. Cordeiro (2005): EST versus genomic derived microsatellite markers for genotyping wild and cultivated barley, Genetic Resources and Crop Evolution 52: 903-909.

Chaib, J., S. Danan, B. Jouaud, L. S. Hagen, F. Lefèvre and B. FADY (2006): Identification and characterization of nuclear microsatellites in Mediterranean cedars (Cedrus sp.). Molecular Ecology Notes 6: 840-842.

Chagné, D., P. Chaumeil, A. Ramboer, C. Collada, A. Guevara, M. T. Cervera, G. G. Vendramin, V. GarCIA, J.-M. Frigerio, C. EChT, T. RICHARDSON and C. Plomion (2004): Cross-species transferability and mapping of genomic and cDNA SSRs in pines. Theoretical and Applied Genetics 109(6): 1204-1214.

Clark, M. C., T. R. Wentworth and D. M. O'Malley (2000): Genteic discontinuity revealed by chloroplast microstallites in Eastern North American Abies (Pinaceae). American Journal of Botany 87(6): 774-782.

Doyle, J. J. and J. L. Doyle (1990): Isolation of plant DNA from fresh tissue. Focus 12: 13-15.

FADY, B., F. LefÈvRe, M. Reynaud, G. G. Vendramin, M. Bou Dagher-Kharrat, M. Anzidei, R. Pastorelli, A. SAVouré and M. BARIteAu (2003): Gene flow among different taxonomic units: evidence from nuclear and cytoplasmic markers in Cedrus plantation forests. Theoretical and Applied Genetics 107(6): 1132-1138.

FAdy, B., F. Lefèvre, G. G. Vendramin, A. Ambert, C. RÉGNIER and M. BARITEAU (2008): Genetic consequences of past climate and human impact on eastern Mediterranean Cedrus libani forests. Implications for their conservation. Conservation Genetic 9: 85-95.

Hodgetts, R. B., M. A. Aleksiuk, A. Brown, C. Clarke, E. MacDonald, S. NADEem and D. Khasa (2001): Development of microsatellite markers for white spruce (Picea glauca) and related species. Theoretical and Applied Genetics 102: 1252-1258.

NEALE, D. B. and R. R. SEDERoff (1989): Paternal inheritance of chloroplast DNA and maternal inheritance of mitochondrial DNA in loblolly pine. Theoretical and Applied Genetics 77: 212-216.
NEI, M. (1987). Molecular evolutionary genetics. Columbia University Press, New York.

Louriex, M., M. N. NDJIONDJOP and A. Ghesauiere (2000): A first interspecific Oryza sativa \& Oryza glaberrima microsatellite-based genetic linkage map. Theoretical and Applied Genetics 100: 593-601.

Provan, J., N. Soranzo, N. J. Wilson, D. B. Goldstein and W. Powell (1999): A low mutation rate for chloroplast microsatellites. Genetics 153: 943-947.

QIAO, C. Y., J. H. RAN, Y. LI and X. Q. WANG (2007): Phylogeny and Biogeography of Cedrus (Pinaceae) Inferred from Sequences of Seven Paternal Chloroplast and Maternal Mitochondrial DNA Regions. Annals of Botany 100: 573-580.

Rajora, O. P., M. H. Rahman, S. Dayanandan and A. MosSELER (2001): Isolation, characterization, inheritance and linkage of microsatellite DNA markers in white spruce (Picea glauca) and their usefulness in other spruce species. Molecular and General Genetics 264: 871-882.

Rao Nageswara, M., B. T. Ramesha, G. Ravikanth, K. N. GANESHAIAH and R. UmA SHAANKER (2006): Crossspecies amplification of coconut microsatellite markers in rattans. Silvae Genetica 56(6): 282-286.

Terrab, A., O. Paun, S. Talavera, K. Tremetsberger, M. ARISTA and T. F. Stuessy (2006): Genetic diversity and population structure in natural populations of Moroccan Atlas cedar (Cedrus atlantica; Pinaceae) determined with cpSSR markers. American Journal of Botany 93: 1274-1280.

TIWARI, D. N. (1994): A monograph on Chir Pine (Pinus roxbuurghii SARG). Indian Council of Forestry Research \& Education, Dehradun, 311 p.

Vendramin, G. G., L. R. Lelli, P. Rossi and M. Morgante (1996): A set of primers for the amplification of 20 chloroplast microsatellites in Pinaceae. Molecular Ecology 5: 595-598.

Vendramin, G. G., M. Anzidei, A. Madaghiele and G. BUCCI (1998): Distribution of genetic diversity in Pinus pinaster Ait. as revealed by chloroplast microsatellites. Theoretical and Applied Genetics 97: 456-463.

Watano, Y., M. IMAZU and T. Shimizu (1996): Spatial distribution of cpDNA and mtDNA haplotypes in a hybrid zone between Pinus pumila and P. parviflora var. pentaphylla (Pinaceae). Journal of Plant Research 109: 403-408.

Weising, K., H. NyBom and K. WolfF (2005): DNA Fingerprinting in Plants Principles, Methods, and Applications. $2^{\text {nd }}$ edn. Taylor \& Francis Group, CRS Press, New York.

Zhou, Y., T. Bui, L. D. Auckland and C. G. Williams (2002): Under-methylated DNA as a source of microsatellites from a conifer genome. Genome 45: 91-99. 